Synætheres dubia.

Lagostomus Brasiliensis.

Dasyprocta capreolus.

Coelogenys laticeps.

C. major.

Kerodon antiquum.

K. bilobidens.

Cavia robusta.

C. gracilis.

Hydrochærus sulcidens.

Megamys Patagonensis, D’Orbigny (genus of which the classification is yet doubtful).

Megatherium Cuvieri, Desm.

Mylodon robustus, Owen.

M. Darwini, Owen.

M. Harlani, Owen.

Megalonyx Kaupii : ? Gnathopsis Oweni, Leidy.

M. Maquinensis.

Scelidotherium leptocephalum, Owen.

S. Cuvieri, Owen.

S. Bucklandi, Owen.

S. minutum: ? S. Brongniarti, Lund.
Calodon Maquinense, Lund.

Sphænodon minutus, Lund. sp.

Glyptodon clavipes, Owen.

G. reticulatus, Owen.

G. tuberculatus $=$ Schistopleurum typus, S. gemmat um and tuberculatum, Nodot.

G. ornatus, Owen.

G. clavicaudatus, Owen.

Hoplophorus euphractus.

H. selloi, Lund.

H. minor.

Pachytherium magnum, Lund.

Chlamydotherium Humboldtii, Lund.

Chlamydotherium s. Ocnotherium gigas, Lund.

Dasypus maximus.

D. antiquus.

D. punetatus.

Euryodon latideus, Lund.

Heterodon diversidens, Lund.

Glossotherium, Owen $=$ Mylodon?

P Abathmodon fossilis, Land.

? Speothos pacivorus, Lind.

\title{
A VISIT TO RECULVER, IN KENT.
}

\author{
Bx Georae D. Gibb, M.D., M.A., F.G.S.
}

Those who are familiar with Sir Charles Lyell's 'Principles of Geology' will remember the illustrations given, in the twentieth chapter of his able and most philosophical book, of the action of the sea on various parts of the coasts of Britain. The changes that have taken place in some parts, even within the historical period, have been very considerable, and perhaps none more so than on the eastern and south-eastern coasts of England, where the encroachments of the sea seem to have been of the most destructive character. From the western coast of the Isle of Sheppey, extending eastwards to Herne Bay, Reculver, and Thanet, the destructive action of both the sea and the other elements has been witnessed by many in our own time; and every year tells its history of a change in some part of this line of const.

I had long contemplated a visit to Reculver, and in the month of June last the opportunity of seeing this part of the coast was afforded me. No place is more accessible from London than Herne Bay; the visitor has the opportunity of running down either by steamer from London Bridge, or by the London, Chatham, and Dover Railway from either the London Bridge or Victoria stations. If time is an object, the latter is preferable, and it was the route I chose, which enabled me to see and learn all that I desired in a single day. 
Leaving London at a quarter-past eight on a fine Sunday morning, in an excursion train, with (as it appeared to myself and others) nearly 1500 people, we made but few stoppages until we reached Faversham, at half-past ten, where those who were going on to Herne Bay had to change carriages. As the next train did not leave for the latter place until ten minutes past eleven, it allowed of time to examine that small but apparently old town. We reached Herne Bay at half-past eleven, stopping at Whitstable on our route. To some persons the journey of three hours and a quarter may appear long, but in reality it is not so, when the distance is considered, enlivened by the number of objects to be seen along the road. The sea is visible for some distance before reaching Herne Bay, and the heights of Sheppey could be very readily distinguished from the south.

The railway station is about half a mile to the south-west of Herne Bay, and the latter seemed to be a larger place than I had anticipated. The pier, which is very long, no doubt marks the boundary of what was once the mainland, washed away by the sea. Immediately opposite the town, the hand of man has provided against further denudation. On arriving at the eastern extremity of the town, the cliffs are reached, here commencing by a gentle ascent. Along their summit I leisurely wended my way to Reculver, some three or four miles distant. A large portion of them had fallen only very lately -indeed, within the past few months, as I was informed; and to some extent I could recognize the deposits as described by Dr. Michell (Proc. Geol. Soc. vol. ii.), i.e. in that part of the cliffs situate between Reculver and Herne Bay, about two miles in extent. "The upper part, where the beds are fully developed, consists of about 35 feet of mottled, brown, and red clay; and the lower part of about 50 feet of sand, containing a layer of masses of sandstone. Fossils are stated to be found only in the sand, and to belong chiefly to a species of Venus."

It was this high part of the cliff which was now chiefly in ruins from late slips, the result of the great rains in early spring. I could observe too, many large slabs of this sandstone strewed along the beach. About halfway I came to a deep ravine, and although the cliff here was very steep, I managed to descend and cross it without going half a mile round. I did not stop now until I arrived at the old church of Reculver, unless occasionally to gaze at it from a distance, its appearance being long familiar to me from the drawings in Sir Charles Lyell's book. I was certainly amply repaid for my visit; here was before me a good illustration of the wear and tear of the land by the sea, aided by the rains. Years ago I was delighted with the description of this pretty spot, and had often expressed the desire to visit it. Speaking of this place, Sir Charles aays, "Still further east stands the church of Reculver, upon a cliff composed of clay and sand, about twenty feet high. Reculver (Regulvium) was an important military station in the time of the Romans, and appears, from Leland's account, to have been, so late as Henry VIII.'s reign, nearly one mile distant from the sea. In the 'Gentleman's Magazine' 
there is a view of it, taken in 1781 , which still represents a considerable space as intervening between the north wall of the churchyard and the eliff. Some time before the year 1780 , the waves had reached the site of the ancient Roman camp, or fortification, the walls of which had continued for several years after they were undermined to overhang the sea, being firmly cemented into one mass. They were eighty yards nearer the sea than the church, and they are spoken of in the 'Topographia Britannica,' in the year 1780, as having recently fallen down. In 1804, part of the churehyard with some adjoining houses was washed away, and the ancient church, with its two lofty spires, a well-known landmark, was dismantled and abandoned as a place of worship. It is still standing (183 ), but would probably have been annihilated ere this, had not the force of the waves been checked by an artificial causeway of stones and large wooden piles driven into the sands to break the force of the waves."

Let us see how matters now are, in 1862, some twenty-eight years after Sir Charles visited it. The towers of the old church still stand

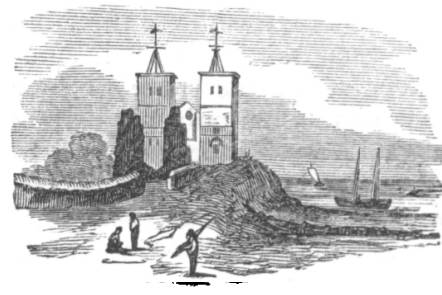

Fig. 1.-View of Reculver, 1848. as represented in the picture in Sir Charles's book, but a large portion of the cliff in front, fully two-thirds, has fallen down, that especially including the hedges; and the burying-ground is now exposed in a line parallel to the front of the church. Besides the groins and the artificial causeway of stunes, to protect this part of the coast, there is an artificial embankment as well, extending to the west of the church. I compared the accompanying reduced copy of a woodcut, made in 1848, of "Reculver, as it is," with the ruins, on the spot. It is very correct as to the towers and remains of walls, with the beacons on the former. But the stone fence there represented is wholly gone. So that the chief alteration round Reculver is the loss of a considerable portion of the cliff in front of the church, and the disappearance of the low wall which surrounded the northern aspect of the latter. The wear and tear of the cliff to the westward, no doubt, has been considerable during the last thirty years, and it appears to be gradually stealing upon the contiguous farmland, as is witnessed at Sheppey.

I examined the old church in every particular, ascended the old spiral stone staircase in the northern tower to the first floor, thence three distinct ladders which lead to the top, and I stood alongside the beacon. As the wind was very strong, I did not remain long, but enjoyed a magnificent view of things in the distance. I could see Margate in one direction, and Sheppey in the other, and likewise far inland to the southward; whilst to the north and east, the sea was seen covered with boats and vessels as far as the eye could reach. On descending to the first floor again, we passed out of a door leading to a sort of friars' walk, which took us across to the other or 
southern tower. Numerous holes were seen inside the walls, in which birds had built their nests; some of them contained young, of the starling especially. I picked up in this tower a few humau bones from the churchyard, collected by the people who had charge of the place, and brought away with me an axis, a clavicle, and a temporal bone, in the usual condition of graveyard specimens.

I now descended to the ground and visited the Roman encampment, at least the remains of it, walking round as much of the old wall as is visible at its eastern and southern faces. It was still very perfect, although in some places undermined, and portions had fallen outwards in some places. Many fragments of genuine Roman brick were observed, which had been built in by the Romans. Occasionally Roman coins are found about here, generally much defaced and in bad condition. Gold rings and other articles are now and then picked up at the base of the exposed wall of the old graveyard, and not unfrequently the end of a coffin becomes exposed, and its contents are soon rifled with the object of finding jewellery.

As an object of antiquity, the remains of the old church are well worthy of preservation. I lingered about Reculver for some hours, and retraced my steps to Herne Bay. From Reculver, and indeed all along the const to Herne Bay, the high land of the east end of Sheppey is a prominent object in the distance. Shoeburyness, on the opposite side of the Thames, can also be seen. South of this place is Herne, which gives its name to what once was a bay. Herne Bay has nothing to boast of but the sea and its long pier, the termination of which shows where the line of coast at one time extended, as we may infer from the Admiralty charts of the present day, which I think very accurately indicate the former position and boundaries of the land by the presence of the shoals of clay and sand. The point of attraction about here is certainly Reculver, but the inhabitants do not appear to know it.

About half way to Rectilver, I picked up on the top of the cliff an undoubted flintimplement in a broken condition, but still sufficiently distinct to point out its real nature. It strongly resembles many of those I have seen, both in colour and shape. The latter is shown in the annexed woodcut. It is not the first time that flint-implements have been found at Reculver, as in the 'Geologist' for July they are referred to, in a review of Mr. Evans's paper on 'Further Discoveries of Flint Implements in the Drift.'

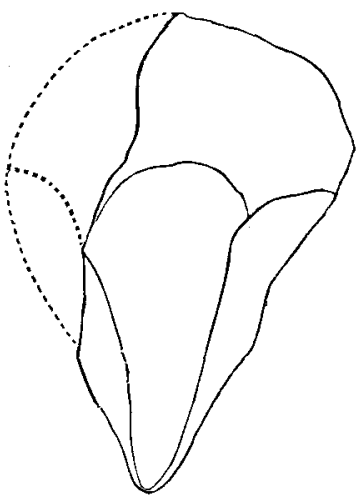

The train which brought me down to Fig. 2.--Small fint implement. Herne Bay left for London at half-past seven, having allowed me eight hours to wander about a part of the coast, which will amply repay a visit. 